\title{
Relevancia de lo marginal e irrelevancia de lo explícito en el juego de la transmisión de la historia en el Quijote
}

\author{
SANTIAgo LóPez NAVIA*
}

\section{El PACTO DEL LECTOR}

"Estos fueron los versos que se pudieron leer; los demás, por estar carcomida la letra, se entregaron a un académico, para que por conjeturas los declarase". En estas palabras del último capítulo del Quijote de $1605^{1}$, referidas a los "versos castellanos" que contenía la caja de plomo hallada en una ermita, se encierra la tensión entre las dos fuerzas que intervienen en la lectura de la obra: lo que se puede leer claramente y lo que se puede declarar por conjeturas. Entre el lector común y el "lector informado" hay una importante diferencia, desde el momento en que el segundo gusta de "declarar por conjeturas", que en un texto como el del Quijote son muchas veces más fuertes que las certezas, pero ambos están unidos en un pacto imprescindible con la obra: para entenderla, hay que "saber", pero sobre todo hay que "jugar a saber".

Sabemos que Cervantes ha escrito un libro en el que se narran las aventuras de don Quijote de la Mancha, y que estas aventuras se distribuyen, a lo

*. Universidad SEK.

1. Cervantes, Miguel de, Quijote, I, 52. Todas nuestras citas del texto se referirán a la parte de la obra, expresada en números romanos, y al capítulo, expresado en números árabes. Por la obviedad de la referencia, y para aliviar en parte el contenido de las notas a pie de página, la obra no se citará en las notas desde la 11 hasta la 25. Seguimos siempre la edición de Martín de Riquer, Barcelona, Planeta, 1980. 
largo de dos partes solidarias pero significativas e interesantes en sí mismas, de acuerdo con una estructura y un despliegue de recursos que se van definiendo a medida que los van estimulando las circunstancias mismas de la escritura -muy especialmente el concepto de consciencia de la propia creacióny las peripecias vitales que afectan al autor y a su obra. Y sabemos lo que sabemos porque hemos aceptado "jugar a saber" que la historia que leemos ha sido escrita por Cide Hamete Benengeli, y que su transmisión se ve sujeta a un juego de voces que suscitan la duda permanente del lector; jugamos a saber que lo que leemos no es sólo lo que ha escrito Benengeli, sino lo que los demás han dicho sobre lo que escribe Benengeli; jugamos a saber que las voces de la narración pueden intervenir en la pretendida literalidad de la obra original, haciendo que su transmisión mediante la paráfrasis que se hace clara en el capítulo I, 9 se presente llena de escollos; jugamos a saber que el mismísimo primer autor es el primero en manifestar sus reservas acerca de lo que escribe... Jugamos, en fin, a aceptar las zonas de sombra de la escritura del texto tanto si son claramente atribuibles a Cervantes como si son el resultado de no poder controlar todos los mecanismos de una obra cuya complejidad será siempre sorprendente.

En ese pacto del lector, más grave y comprometido en el caso del "lector informado", intervienen también otras inferencias que afectan al juego de la transmisión del texto. El lector informado en que acaba convirtiéndose todo aquel que intenta leer con cierta profundidad juega a saber, por ejemplo, que don Quijote escribió, durante su penitencia en Sierra Morena, muchos más versos de "los que se pudieron hallar enteros y que se pudiesen leer después que a él allí le hallaron"2, así como que en las bodas de Camacho se recitaron muchos más versos porque sólo nos han llegado los que don Quijote "tomó de memoria" 3 y que, volviendo al contexto en el que se insertan las líneas que abren esta introducción, la caja de plomo hallada en la ermita contenía muchos más versos, porque los de los académicos de la Argamasilla son tan sólo "los que se pudieron leer y sacar en limpio".

En este trabajo nos proponemos profundizar en el estudio de algunos contextos que forman parte del entramado lúdico de la transmisión de la historia en el Quijote y que nos hacen reflexionar en el sentido de que lo que se expresa al margen -siempre según lo que "jugamos a saber" - puede ser relevante, y lo que a veces es explícito puede ser lúdicamente irrelevante, y lo haremos conscientes de que tendremos que "declarar por conjeturas", hasta donde nos sea posible, en todos aquellos casos en los que no podamos conformarnos con "leer". Ya estamos acostumbrados a aceptar que el estudio de los problemas del texto del Quijote es más capaz, muchas veces, de sugerir preguntas que de alumbrar respuestas, y mucho menos respuestas definitivas.

2. Cervantes, Quijote, I, 26.

3. Cervantes, Quijote, II, 20. 


\section{2. "EN EL MARGEN ESCRITO": CUANDO LO MARGINAL PUEDE SER RELEVANTE 4}

\subsection{Un detalle escrito al margen e incorporado a la superficie textual: el hallazgo del manuscrito en el capítulo I, 9}

En la transición narrativa que definen los primeros párrafos del capítulo I, 9 , que ya hemos estudiado ${ }^{5}$, el narrador-segundo autor, que ahora se expresa en primera persona, transcribe literalmente las explicaciones que aduce el traductor acerca de las razones por las que la lectura del manuscrito recién encontrado en el Alcaná de Toledo suscita su risa y da cuenta, a continuación, de otros detalles del cartapacio que conviene tener muy en cuenta para nuestro trabajo:

-Está, como he dicho, aquí en el margen escrito esto: "Esta Dulcinea del Toboso, tantas veces en esta historia referida, dicen que tuvo la mejor mano para salar puercos que otra mujer de toda la Mancha".

Cuando yo oí decir "Dulcinea del Toboso", quedé atónito y suspenso, porque luego se me representó que aquellos cartapacios contenían la historia de don Quijote. Con esta imaginación, le di priesa que leyese el principio, y haciéndolo ansí, volviendo de improviso el arábigo en castellano, dijo que decía: Historia de don Quijote de la Mancha, escrita por Cide Hamete Benengeli, historiador arábigo (...)

Estaba en el primero cartapacio pintada muy al natural la batalla de don Quijote con el vizcaíno (...) Tenía a los pies escrito el vizcaíno un título que decía: Don Sancho de Azpeitia, que, sin duda, debía de ser su nombre, y a los pies de Rocinante estaba otro que decía: Don Quijote. Estaba Rocinante maravillosamente pintado, tan largo y tendido, tan atenuado y flaco, con tanto espinazo, tan hético confirmado, que mostraba bien al descubierto con cuánta advertencia y propriedad se le había puesto el nombre de Rocinante. Junto a él estaba Sancho Panza, que tenía del cabestro a su asno, a los pies del cual estaba otro rétulo que decía: Sancho Zancas, y debía de ser que tenía, a lo que mostraba la pintura, la barriga grande, el talle corto y las zancas largas, y por esto se le debió de poner nombre de Panza y de Zancas, que con estos dos sobrenombres le llama algunas veces la historia. Otras algunas menudencias había que advertir, pero todas son de poca importancia y que no hacen al caso a la verdadera relación de la historia, que ninguna es mala como sea verdadera.

4. Pretendemos desarrollar en este apartado lo que apuntamos muy brevemente en el apartado 5 de nuestro trabajo "Las distorsiones de la literalidad en el recurso a las fuentes de la historia en el Quijote. La paráfrasis imposible”, Anales Cervantinos, 35, 1999, págs. 263-273.

5. LÓPEZ NAVIA, Santiago, La ficción autorial en el Quijote y en sus continuaciones e imitaciones, Madrid, Universidad Europea de Madrid-CEES Ediciones, 1996, págs. 90-97. Esta transición debe ser entendida en relación con el último párrafo del capítulo I, 8. 
La primera observación importante que nos interesa hacer es que el narrador-segundo autor incorpora a la superficie textual de la historia que leemos un detalle escrito al margen del manuscrito de la misma historia. Un elemento de la estructura profunda de la historia, de acuerdo con el juego de su transmisión, forma parte ahora, a través del narrador, no sólo de lo que el traductor lee al margen del texto, sino también de lo que el lector lee en el texto mismo, con lo cual se consigue el efecto de integrar en la historia un detalle que inicialmente no formaba parte de ella en términos estrictamente textuales. El lector, por lo tanto, no sólo accede en este juego al resultado final de la transmisión de la historia, sino a todas las circunstancias de su arquitectura lúdica, y conoce así un dato fundamental sobre un personaje tan determinante como es Dulcinea del Toboso, acerca de la cual, y de forma muy significativa, conocemos todo lo que conocemos gracias a lo que dice Sancho en el capítulo I, 25. Hasta que llega este momento en el que Sancho Panza reconoce en Aldonza Lorenzo la verdadera identidad de Dulcinea del Toboso y desbroza ante el lector una descripción groseramente alejada de toda idealidad, y antes de la información significativa que encierra el dato "en el margen escrito" que ahora estamos analizando, sólo sabemos por el narrador, en el capítulo I, 1, que Dulcinea es el nombre elegido por don Quijote para "una moza labradora de muy buen parecer". Todo ello añadido, recordémoslo una vez más, al hecho de que sabemos lo que sabemos de Dulcinea por lo que de ella se dice, nunca por lo que ella dice ${ }^{6}$. No por casualidad la anotación marginal deja clara su condición de "tantas veces en esta historia referida".

Aunque gracias a él conocemos este nuevo dato sobre Dulcinea del Toboso, ahora la fuente de la información no es la voz del narrador, sino una anotación escrita al margen cuya procedencia no podemos identificar fácilmente. Obviamente, y a diferencia de las ocasiones en las que interviene en el texto, el autor de esta anotación no es el traductor, que es el primero que la lee, y tampoco es el narrador-segundo autor, que da cuenta de ella al lector. ¿Es, por lo tanto, una anotación marginal de Cide Hamete Benengeli, que sí es el autor de la que luego estudiaremos, o refleja la intervención de alguna de las fuentes indefinidas que tanta importancia tienen en el despliegue del complejo recurso de la pseudohistoricidad en el Quijote? Nada nos autoriza a aducir una respuesta infalible. Lo que sí está muy claro es que el autor de la anotación tiene en cuenta a su vez a las fuentes indefinidas, inequívocamente representadas en el recurrente "dicen"7, y que su contenido sirve para delimitar al personaje en las coordenadas de su dimensión social real, lejos -paródicamente

6. La autonomía dialógica de Dulcinea del Toboso empieza con el Quijote de Avellaneda. Ver LóPEZ NAVIA, Santiago, "Guía breve de Dulcineas", Inspiración y pretexto. Estudios sobre las recreaciones del Quijote, Madrid, Iberoamericana-Vervuert, 2005, págs. 51-67.

7. Para este concepto y para esta fórmula, véase "La función de las fuentes indefinidas en el Quijote y en su continuaciones e imitaciones", recogido en las págs. 136-146 de nuestro trabajo citado en la nota anterior. 
lejos- de la reinvención idealizada del protagonista. La combinación del dato escrito al margen con las fuentes indefinidas obtiene un resultado claro en el juego de la transmisión y construcción de la historia: un dato de descarnador realismo, relativo a un personaje principal de la historia, que no pertenece al cuerpo textual de la historia misma en su origen y que, por si fuera poco, es atribuible a una fuente indefinida cuyo compilador, conjeturas aparte, nos es desconocido.

Tampoco sabemos nada sobre el autor de los dibujos del primer cartapacio. La presencia de los dibujos, además, es de todo punto excepcional en toda la obra, y no hay, desde la historia -construcción, transmisión y narración del texto-, ninguna otra referencia a dibujos de sus personajes, de modo que los que ahora se describen pueden considerarse también, en cierto sentido, marginales. Sólo gracias a las anotaciones -¿de quién?- que complementan a estos dibujos conocemos el nombre del vizcaíno, hasta ahora desconocido, y sólo gracias a estas anotaciones sabemos que Sancho Panza aparece ahora con el sobrenombre de "Sancho Zancas", cuyo sentido se nos explica ("que con estos dos sobrenombres le llama algunas veces la historia"). Y esto es lo fundamental: ¿qué historia? Y esta pregunta tiene sentido porque no volveremos a leer nunca este sobrenombre, que aparece fuera de la historia y que el narrador-segundo autor, que es quien describe los dibujos y da cuenta de las anotaciones que los explican, refiere precisamente a la historia misma. Si no tenemos, más allá del dato que aparece al pie del dibujo, constancia del sobrenombre "Zancas" ni antes ni después de la descripción de los dibujos del primer cartapacio, ¿qué tenemos que suponer? Cabe interpretar que el dato no es significativo, dada su condición de dato aislado; cabe entender, quizá, concediendo cierta perfección consciente a la elaboración del juego, que se pretende sugerir que esos fragmentos de la historia en los que se llama a Sancho con los dos sobrenombres mencionados se han perdido o han sido obviados por las voces de la narración.

Acaso, y como en otros contextos del Quijote, la interpretación menos forzada permita deducir que la incoherencia entre este dato y su inexistente reflejo en la historia, pese a lo que explica el narrador, es una nueva señal de la falta de control, tantas veces puesta en evidencia, que ocasionalmente demuestra Cervantes sobre su propia obra.

Sin embargo, cuando leemos que "otras algunas menudencias había que advertir, pero todas son de poca importancia y que no hacen al caso a la verdadera relación de la historia", sí que está claro, y muy claro, que es el segundo autor el que selecciona qué datos -dibujos o nombres- de la historia son o no "menudencias" que afectan a "la verdadera relación de la historia". Y si hay algunas desestimadas con este criterio, ¿debemos entender que las anteriores tienen más importancia y afectan a esa "verdadera relación"?

Aunque sería un ejercicio muy grato, renunciemos a la fácil tentación de rizar el rizo y aceptemos cuanto antes que la contestación es impertinente: o no importa, o no es posible. Así pues, conformémonos con quedarnos, una vez más, en la pregunta. 


\subsection{Las dudas de Cide Hamete Benengeli, expresadas al margen}

Centrémonos ahora en el estudio del comienzo del capítulo II, 24, uno de esos capítulos cuyo título resulta significativo a la luz de los criterios que más adelante tendremos en cuenta:

Dice el que tradujo esta grande historia del original de la que escribió su primer autor Cide Hamete Benengeli, que llegando al capítulo de la aventura de la cueva de Montesinos, en el margen dél estaban escritas de mano del mesmo Hamete estas mismas razones:

"No me puedo dar a entender, ni me puedo persuadir, que al valeroso don Quijote le pasase puntualmente todo lo que en el antecedente capítulo queda escrito: la razón es que todas las aventuras hasta aquí sucedidas han sido contingibles y verisímiles; pero ésta desta cueva no le hallo entrada alguna para tenerla por verdadera, por ir tan fuera de los términos razonables. Pues pensar que don Quijote mintiese, siendo el más verdadero hidalgo y el más noble caballero de sus tiempos, no es posible; que no dijera él una mentira si le asaetearan. Por otra parte, considero que él la contó y la dijo con todas las circunstancias dichas, y que no pudo fabricar en un breve espacio tan gran máquina de disparates; y si esta aventura parece apócrifa, yo no tengo la culpa; y así, sin afirmarla por falsa o verdadera, la escribo. Tú, letor, pues eres prudente, juzga lo que te pareciere, que yo no debo ni puedo más; puesto que se tiene por cierto que al tiempo de su fin y muerte dicen que se retrató della, y dijo que él la había inventado, por parecerle que convenía y cuadraba bien con las aventuras que había leído en sus historias".

No es la primera vez que reflexionamos sobre este fragmento ${ }^{8}$, pero vamos a detenernos ahora en los detalles que afectan al entramado de la arquitectura textual. Es muy evidente, para empezar, que en estos dos párrafos el lector no está leyendo la historia, sino las circunstancias de la metahistoria, que vuelven a formar parte una vez más de la superficie textual: el segundo autor-narrador nos cuenta que el traductor dice que Cide Hamete Benengeli escribe al margen lo que a continuación se transcribe literalmente, una vez traducido. El lector accede nuevamente a las dos principales dimensiones de la historia en el juego de la construcción del Quijote: la "historia original" escrita por Benengeli, en la que se cuentan las aventuras de don Quijote y Sancho Panza, y la "historia de la historia", en la que se detallan no sólo las circunstancias del hallazgo, traducción y transmisión de la "historia original", sino las opiniones críticas de las diferentes voces de la narración acerca de lo que cuentan y traducen. El lector informado sabe que la superficie del texto, suma de la "historia original" que escribe el primer autor y la "historia de la historia" que narra

8. En otra ocasión analizamos con detalle el contenido de estos dos párrafos, centrándonos en los factores que demuestran el juego del seguimiento de los personajes del Quijote por parte del mismo Cide Hamete Benengeli. Ver LóPez NaVia, Santiago, La ficción autorial en el Quijote y en sus continuaciones e imitaciones, págs. 110-112. 
el segundo autor, ha sido escrita por Cervantes, pero también tiene que aceptar jugar a saber que la urdimbre de la arquitectura textual, el recurso de la estructura profunda de la historia, es el resultado de la intervención y de la interacción, muchas veces contradictoria -lúdicamente contradictoria-, de las voces de la narración.

Dicho esto, cuando el narrador nos dice que Cide Hamete escribió lo que escribió al margen, nos hace saber muy claramente que esto ocurre "llegando al capítulo de la aventura de la cueva de Montesinos". Sin embargo, esa aventura no transcurre en el capítulo II, 24, en el que leemos el fragmento que ahora nos interesa, sino en el capítulo II, 23. Intentemos entenderlo bien: estamos leyendo en el capítulo II, 24 las "razones" que formaban parte -insistimos- del "capítulo de la aventura de la cueva de Montesinos", que es el anterior, de lo cual se sigue que la organización de los capítulos del texto traducido que el narrador nos cuenta no coincide con la organización de los capítulos de la historia original, y ello independientemente de que Cervantes haya pretendido o no inducirnos a extraer esta conclusión. No es posible saber si Cervantes ha controlado conscientemente esta parte de su juego, pero el juego mismo sugiere esta lectura; en el mismo sentido, la expresión textual del juego nos invita a suponer que no ha sido Cide Hamete Benengeli quien ha puesto nombre a los capítulos, porque de otra manera no sería posible un título como el del capítulo II, 28 ("De cosas que dice Benengeli que las sabrá quien le leyere, si las lee con atención"), salvo que acudiésemos a explicaciones cuyo despliegue argumental sería tan prolijo como impertinente. A partir de aquí, y con la misma prudencia que en otras ocasiones, no nos consideramos en condición de afirmar si Cervantes ha definido todas estas aristas de su propio despliegue recursivo o si estos efectos, que nos parecen claros, se imponen con independencia de la voluntad y el control de su creador.

Lo que está claro, y muy claro, siempre dentro del juego, es que lo que está al margen se incorpora a la superficie textual y ha sido escrito precisamente por el mismo Benengeli, a diferencia de la anotación marginal del capítulo I, 9, antes estudiada, en cuyo contexto nos faltaban las referencias de las voces de la narración que ahora no dejan lugar a dudas. La única referencia común por parte del narrador es la que atañe al traductor, que en ambos casos da cuenta de una anotación al margen. Por lo demás, lo que se contiene en el margen, una vez más, es un dato de tan obvia relevancia como suponen las dudas del primer autor sobre la verdad de lo que cuenta el protagonista acerca de su descenso a la cueva de Montesinos. Ya hemos analizado en qué medida esta intervención de Benengeli significa una ruptura lúdica de la omnisciencia atribuible a alguien que se nos presenta recurrentemente como un "sabio historiador"9; ahora añadimos que el hecho de sugerir la falsedad de esta aventura por lo que se afirma en relación con lo que don Quijote dice al respecto "al

9. En el mismo trabajo citado en la nota anterior, págs. 114-122. 
tiempo de su fin y muerte" supone una nueva ruptura de la omnisciencia, porque Cide Hamete debería saber con la autoridad que se le atribuye qué es lo que "se tiene por cierto" o no. Es el caso que ese mismo Cide Hamete, cuya voz vuelve a oírse -o sea, a leerse- literalmente al final del capítulo II, 74, tras la muerte de don Quijote, vuelve a depender al comienzo del capítulo II, 24 del testimonio de las fuentes indefinidas, representadas una vez más por el reconocible "dicen" -que también se manifestó en la anotación al margen del capítulo I, 9, en el que, al igual que ahora, el contenido de la anotación se transcribe literalmente, fuera de la paráfrasis del narrador-segundo autor- $y$ es también el caso que este mismo Cide Hamete que no sabe decidirse ahora acerca de la verdad de la aventura narrada por el protagonista de su historia original, y por extensión acerca de la credibilidad del protagonista, es el mismo autor de la historia en la que don Quijote y Sancho Panza suscriben un quid pro quo que sella uno de los pactos más fuertes (y más perversos) que dos personas pueden suscribir: el reconocimiento cómplice en la mentira, como puede leerse al final del capítulo II, 41, después de que Sancho invente el disparate de su vuelo a lomos de Clavileño:

- Sancho, pues vos queréis que se os crea lo que habéis visto en el cielo, yo quiero que vos me creáis a mí lo que vi en la cueva de Montesinos. Y no os digo más.

Demasiado complejo y elaborado para no ser casual. Sinceramente, asumiendo el riesgo de equivocarnos, y a pesar de que el control sobre su obra se incremente en el Quijote de 1615, no creemos que todos estos ingredientes definan un plan de escritura deliberadamente urdido por Cervantes. El juego se impone, quizá, mucho más allá de las previsiones de su creador.

\section{CUANDO LO EXPLÍCITO PUEDE SER LÚDICAMENTE IRRELEVANTE: LOS TÍTULOS DE ALGUNOS CAPÍTULOS}

Nos centraremos a continuación en algunos títulos de capítulos del Quijote cuyo contenido es parcial o totalmente carente de una información relevante, lo cual no implica, ni mucho menos, que carezcan de importancia ${ }^{10}$ tanto en relación con el universo literario al que se refieren como en la construcción de la obra.

Según su estructura, los títulos que nos interesan pueden ser bimembres o unimembres, entendiendo esta categoría desde el punto de vista de la presencia de los contenidos en su construcción. En los títulos bimembres reconocemos una parte que afecta al contenido principal del capítulo y otra de carácter general e indefinido. Este segundo elemento se introduce mayoritariamente

10. La relación completa de títulos considerados en esta parte de nuestro trabajo se detalla en el "Apéndice", al que remitimos. 
mediante la preposición $\operatorname{con}^{11} \mathrm{y}$, en menor proporción, mediante la conjunción copulativa $y^{12}$. Al igual que no nos resulta fácil arriesgar una explicación convincente y acaso innecesaria sobre el hecho de que este tipo de títulos bimembres aparezcan desde el capítulo I, 8, en el que se refiere la primera aventura compartida por la pareja protagonista, es muy significativo que los títulos de estructura unimembre, por lo que después veremos, se den exclusivamente en el Quijote de 1615 como una muestra más de la conciencia y el dominio que demuestra Cervantes de su propia obra. Como más adelante haremos notar, son estos títulos de estructura unimembre los que nos parecen más representativos de la intención lúdica del autor.

En cuanto a la formulación de sus elementos, la segunda parte de los títulos de estructura bimembre se basa en palabras clave de valor semántico escasamente relevante en su contexto reducido. Un primer subgrupo de títulos hace descansar el valor indefinido de su segundo miembro en la palabra clave "sucesos"13 y en palabras semánticamente próximas, como "aventuras"14 (palabra de especial valor, como ya sabemos, en la literatura caballeresca), "acaecimientos"15, y "acontecimientos"16. Otro segundo subgrupo igualmente representativo por el número de títulos que comprende despliega su segundo miembro en torno a la palabra clave "cosas"17. Anotamos, fuera de los dos subgrupos anteriores, el título del capítulo II, 62, en cuyo segundo miembro la palabra clave es "niñerías", un poco más cargada de valor connotativo sin que deje de ser indefinida.

La formulación de los títulos de estructura unimembre basa su valor en su contenido impreciso ${ }^{18}$, cuando no claramente tautológico ${ }^{19}$ o a un tiempo impreciso y tautológico ${ }^{20}$. Por otra parte, en casi todos puede apreciarse una palabra clave de carácter igualmente impreciso, como "cosas" $21 \mathrm{o}$, en un caso aislado, "zarandajas"22.

Tanto en los títulos de estructura bimembre como en los de estructura unimembre hay que hacer notar los mecanismos connotativos al servicio de la pa-

11. I, 8; I, 13; I, 14; I, 18; I, 19; I, 21; I, 27; I, 30; I, 31; I, 36; I, 37; I, 43; I, 47; I, 48; I, 50; II, 2; II, 4; II, 7; II, 18; II, 21; II, 26; II, 32; II, 35; II, 42; II, 48; II, 51; II, 61; II, 62; II, 67 y II, 73.

12. I, 42: I, 45; II, 5; II, 10; II, 55 y II, 65.

13. I, 8; I, 13; I, 14; I, 31; I, 36; I, 47; II, 2; II, 4; II, 5; II, 7; II, 10; II, 21; II, 32; II, 35; II, 51; II, 67 y II, 73.

14. I, 18, I, 37 y "aventuras sucedidas" (I, 45).

15. I, 43 .

16. I, 19 y II, 48.

17. I, 21 ("cosas sucedidas", también semánticamente equivalente, por tanto, a "sucesos"); I, 27; I, 30; I, 42; I, 48; II, 18; II, 26; II, 42; II, 55 (donde la palabra "cosas" se expresa en la primera parte del título y se sobreentiende en la segunda); en II, 61 la palabra "cosas" es, quizá, la que puede sobreentenderse más fácilmente en la segunda parte del título a pesar de no haber sido expresada en la primera.

18. II, 24 y II, 31

19. II, 9 y las parejas de títulos de evidente relación II, 28-II, 66 y II, 40-II, 54.

20. II, 70 .

21. II, 28; II, 31; II, 40; II, 54 y II, 70.

22. II, 24. En este contexto la palabra "zarandajas" adquiere una connotación próxima a "niñerías" en II, 62. 
labra clave, que aportan con bastante claridad, casi siempre, un valor irónico o lúdico. El esquema más común consiste en el uso de adjetivos, bien únicos (antepuestos o pospuestos), bien múltiples o bien complementados ${ }^{23}$, y en menor medida, y sólo en el Quijote de 1615, en proposiciones subordinadas adjetivas o de relativo ${ }^{24}$. En algún caso se emplean complementos del nombre $^{25}$.

Siendo, como es, bastante clara la intención paródica en la que Cervantes carga las tintas, conviene tener en cuenta que este aspecto de la composición de la obra es parte de un patrón literario que puede rastrearse tanto en la literatura caballeresca como en la narrativa áurea española anterior y posterior al Quijote ${ }^{26}$. Por citar algunos casos del primer grupo, en el Amadís de Gaula de Garci Rodríguez de Montalvo (1508) encontramos algunos capítulos cuya segunda parte consiste en una referencia imprecisa a sucesos o acontecimientos indeterminados, una vez definido en su primera parte el contenido fundamental del capítulo ${ }^{27}$. Los ejemplos son mucho más numerosos en Espejo de príncipes y caballeros de Diego Ortúñez de Calahorra $(1555)^{28}$, y lo mismo podemos decir de Flor de caballerías de Francisco

23. I, 8; I, 14; I, 18; I, 19; I, 21; I, 27; I, 36; I, 37; I, 42; I, 43; I, 45; I, 47; I, 48; II, 2; II, 4; II, 5; II, 7; II, 10; II, 18; II, 21; II, 24; II, 26; II, 31; II, 32; II, 34; II, 35; II, 42; II, 48; II, 51; II, 54; II, 55; II, 67 y II, 70. Son especialmente significativas, en estos títulos, las diferentes estructuras consistentes en un complemento del adjetivo "digno/a" en singular y plural (I, 8; I, 18; I, 27; I, 42; I, 48; II, 4; II, 5 y II, 48).

24. II, 28; II, 40; II, 61; II, 62 y II, 73.

25. I, 30 .

26. Aunque el matiz sea sutil, procuramos diferenciar con claridad los títulos cuyas segundas partes son claramente imprecisas y generales de aquellos en los que la segunda parte supone, aunque de forma en efecto imprecisa, una clara alusión a la primera parte. Esta distinción afecta, por ejemplo, al Tirante el Blanco (1490) de Joanot MARTORELL y Martí Joan DE GALBA (seguimos la edición de Martín de Riquer, Madrid, Espasa-Calpe, 1975), en el que apreciamos esta singularidad en títulos de capítulos como el del II, 6 ("Cómo Tirante se partió de Cecilia para ir a socorrer a Rodas, y de lo que pasó antes que en ella se entrase") o el III, 4 ("Cómo la Infanta, hija del Emperador, habló con Diafebus, y de las cosas que entre ellos pasaron"). Es también el esquema de las segundas partes de los títulos del Lazarillo (1554; seguimos la edición de Alberto Blecua, Madrid, Castalia, 1974) desde el tratado segundo hasta el séptimo; véase, por ejemplo, el título del tratado quinto ("Cómo Lázaro se asentó con un buldero y de las cosas que con el pasó"). Lo mismo podemos decir del Guzmán de Alfarache de Mateo Alemán (1599; seguimos la edición de Enrique Miralles García, Barcelona, Bruguera, 1982); véase, por ejemplo, el título del capítulo III, 7 ("Cómo Guzmán de Alfarache sirvió de paje a monseñor ilustrísimo cardenal y lo que le sucedió").

27. Es el caso del capítulo I, 21 ("Cómo don Galaor llegó a un monasterio muy llagado y estuvo allí quince días, en fin de los cuales fue sano, y lo que después le sucedió”) y II, 59 ("De cómo el rey Cildadán y don Galaor fueron llevados para curar y fueron puestos el uno en una fuerte torre de mar cercada, el otro en un vergel de altas paredes y de vergas de hierro adornado, donde cada uno de ellos en sí tomado, pensó de estar en prisión, no sabiendo por quién allí eran traídos y de lo que más les avino"). Seguimos la edición de José Manuel Cacho Blecua, Madrid, Cátedra, 1987.

28. Entre otros muchos ejemplos, y ateniéndonos exclusivamente al libro primero con el ánimo de no ser exhaustivos, anotamos el título del capítulo I, 2 ("Cómo el rey de Hungría, pretendiendo tener derecho al imperio griego, se levantó contra el emperador Trebacio, y con lo que más avino"), o el del capítulo I, 27 ("Cómo la princesa Briana descubrió a Rosicler el secreto de como era su hijo, con lo que más pasó”). Seguimos la edición de Daniel Eisenberg, Madrid, Espasa-Calpe, 1975. 
Barahona (1599 $)^{29}$. En cuanto a la narrativa de los Siglos de Oro publicada con posterioridad al Quijote, este tipo de títulos de segunda parte imprecisa, en aquellos cuya primera parte no resulta mucho más definida, está significativamente representado en el libro segundo del Buscón de Quevedo $(1626)^{30}$.

La gran singularidad que caracteriza a la elaboración de los títulos que hemos estudiado en el Quijote es la intención lúdica que motiva a Cervantes, que los convierte, muy especialmente en la segunda parte, en fórmulas de enlace y continuidad entre capítulos cuyo principal valor consiste precisamente en el recurso de jugar a no tener valor, porque su imprecisión no es un error de formulación sino, muy al contrario, un innegable acierto. Como ya hemos anticipado, no es nada casual que los títulos más significativamente lúdicos se concentren en la segunda parte de la novela, en la que el despliegue metaliterario está mucho mejor urdido desde la consciencia comprometida de la escritura. Baste con reparar de forma especial en el título del capítulo II, 24 ("Donde se cuentan mil zarandajas tan impertinentes como necesarias al verdadero entendimiento desta grande historia"), cuya construcción es un ejemplo de juego paradójico: por definición, las zarandajas, por su connatural falta de sustancia y de interés, no pueden servir al verdadero entendimiento de historia alguna, grande o pequeña, y en ningún caso pueden, de acuerdo con la lógica más elemental, ser al mismo tiempo impertinentes y necesarias. Al igual que ocurre con los ingredientes de la ficción autorial y la pseudohistoricidad, que multiplican su presencia y su eficacia, la construcción de los títulos se hace más elaborada en el Quijote de 1615, dejando traslucir un mayor control y un mejor y más evidente efecto en lograda consonancia con la naturaleza paródica de la obra.

Tanto las anotaciones al margen que hemos reconocido como relevantes en los capítulos I, 9 y II, 24 como los títulos que, muy especialmente en la segunda parte del Quijote, hemos considerado lúdicamente irrelevantes en su formulación, son el resultado de incorporar a la superficie textual los detalles del juego de la transmisión y la reorganización de la historia original. Es muy evidente -juguemos una vez más a saber- que esta incorporación rompe cuanto hay de puramente literal en esta historia original: por lo que toca al juego de la transmisión, los detalles de lo que denominamos "historia de la historia" no pertenecen a la Historia de don Quijote de la Mancha, escrita por Cide Ha-

29. Ciñéndonos también al primer libro, por la misma razón, y a título de ejemplo, encontramos esta estructura en los capítulos I, 8 ("Cómo los emperadores entraron en Constantinopla y del nacimiento del príncipe Belinflor y lo que más sucedió”), I, 11 ("Cómo estando la emperatriz Floriana en las selvas de Grecia fue robada y lo que más le sucedió") o I, 36 ("Cómo el valeroso príncipe Rugerindo mató al malvado Abacundo y lo que más le sucedió”). Empleamos la edición de José Manuel Lucía Megías, Madrid, Centro de Estudios Cervantinos, 1997.

30. Véanse los títulos de los capítulos II, 2 ("En que se prosigue la materia comenzada y otros raros sucesos"); II, 6 ("En que prosigue lo mismo con otros varios sucesos"); II, 7 ("En que se prosigue el cuento, con otros sucesos y desgracias notables") y II, 8 ("De mi cura y otros sucesos peregrinos”). Seguimos la edición de Domingo Ynduráin, Madrid, Espasa-Calpe. 1979. 
mete Benengeli, historiador arábigo, recuperada en I, 9, y por lo que toca a su reorganización, aunque la aplicación del concepto de juego haga precisa una argumentación más sutil y menos comprometida y podamos aceptar sin temor a equivocarnos que las inferencias que invitan a extraer los títulos de los capítulos estudiados vayan más allá de la intención creativa de Cervantes, parece claro que el criterio que rige la distribución de los capítulos y su formulación no hacen nada fácil entenderlos en el seno de la historia original tal como, siempre de acuerdo con lo que jugamos a saber, la escribió su apócrifo primer autor.

Sea como sea, seguiremos intentando "leer y sacar en limpio".

\section{Apéndice \\ Relación de títulos estudiados}

\section{Primera parte}

Del buen suceso que el valeroso don Quijote tuvo en la espantable y jamás imaginada aventura de los molinos, con otros sucesos dignos de felice recordación (I, 8)

Donde se da fin al cuento de la pastora Marcela, con otros sucesos (I,13)

Donde se ponen los versos desesperados del difunto pastor, con otros no esperados sucesos $(1,14)$

Donde se cuentan las razones que pasó Sancho Panza con su señor don Quijote, con otras aventuras dignas de ser contadas (I, 18)

De las discretas razones que Sancho pasaba con su amo y de la aventura que le sucedió con un cuerpo muerto, con otros acontecimientos famosos (I, 19)

Que trata de la alta aventura y rica ganancia del yelmo de Mambrino, con otras cosas sucedidas a nuestro invencible caballero (I, 21)

De cómo salieron con su intención el cura y el barbero, con otras cosas dignas de que se cuenten en esta grande historia (I, 27)

Que trata de la discreción de la hermosa Dorotea con otras cosas de mucho gusto y pasatiempo (I, 30)

De los sabrosos razonamientos que pasaron entre don Quijote y Sancho su escudero, con otros sucesos (I, 31)

Que trata de la brava y descomunal batalla que don Quijote tuvo con unos cueros de vino tinto, con otros raros sucesos que en la venta le sucedieron $(\mathrm{I}, 36)$

Que trata donde se prosigue la historia de la famosa infanta Micomicona, con otras graciosas aventuras (I, 37)

Que trata de lo que más sucedió en la venta y de otras muchas cosas dignas de saberse (I, 42)

Donde se cuenta la agradable historia del mozo de mulas, con otros estraños acaecimientos en la venta sucedidos (I, 43)

Donde se acaba de averiguar la duda del yelmo de Mambrino y de la al- 
barda y otras aventuras sucedidas, con toda verdad (I, 45)

Del estraño modo con que fue encantado don Quijote de la Mancha, con otros famosos sucesos (I, 47)

Donde prosigue el canónigo la materia de los libros de caballerías, con otras cosas dignas de su ingenio $(\mathrm{I}, 48)$

De las discretas altercaciones que don Quijote y el canónigo tuvieron, con otros sucesos (I, 50)

\section{Segunda parte}

Que trata de la notable pendencia que Sancho Panza tuvo con la sobrina y ama de don Quijote, con otros sucesos graciosos (II, 2)

Donde Sancho Panza satisface al bachiller Sansón Carrasco de sus dudas y preguntas, con otros sucesos dignos de saberse y de contarse (II, 4)

De la discreta y graciosa plática que pasó entre Sancho Panza y su mujer Teresa Panza, y otros sucesos dignos de felice recordación (II, 5)

De lo que pasó don Quijote con su escudero, con otros sucesos famosísimos (II, 7)

Donde se cuenta lo que en él se verá (II, 9)

Donde se cuenta la industria que Sancho tuvo para encantar a la señora Dulcinea, y de otros sucesos tan ridículos como verdaderos (II, 10)

De lo que sucedió a don Quijote en el castillo o casa del Caballero del Verde Gabán, con otras cosas extravagantes (II, 18)

Donde se prosiguen las bodas de Camacho, con otros gustosos sucesos (II, 21)

Donde se cuentan mil zarandajas tan impertinentes como necesarias al verdadero entendimiento desta grande historia (II, 24)

Donde se prosigue la graciosa aventura del titerero, con otras cosas en verdad harto buenas (II, 26)

De cosas que dice Benengeli que las sabra quien le leyere, si las lee con atención (II, 28)

Que trata de muchas y grandes cosas (II, 31)

De la respuesta que dio don Quijote a su reprehensor, con otros graves y graciosos sucesos (II, 32)

Que se cuenta de la noticia que se tuvo de cómo se había de desencantar la sin par Dulcinea del Toboso, que es una de las aventuras más famosas deste libro (II, 34)

Donde se prosigue la noticia que tuvo don Quijote del desencanto de Dulcinea, con otros admirables sucesos (II, 35)

De cosas que atañen y tocan a esta aventura y a esta memorable historia (II, 40)

De los consejos que dio don Quijote a Sancho Panza antes que fuese a gobernar la ínsula, con otras cosas bien consideradas (II, 42)

De lo que le sucedió a don Quijote con doña Rodríguez, la dueña de la duquesa, con otros acontecimientos dignos de escritura y de memoria eterna (II, 48) 
Del progreso del gobierno de Sancho Panza, con otros sucesos tales como buenos (II, 51)

Que trata de cosas tocantes a esta historia, y no a otra alguna (II, 54)

De cosas sucedidas a Sancho en el camino, y otras, que no hay más que ver (II, 55)

De lo que le sucedió a don Quijote en la entrada de Barcelona, con otras que tienen más de lo verdadero que de lo discreto (II, 61)

Que trata de la aventura de la cabeza encantada, con otras niñerías que no pueden dejar de contarse (II, 62)

Donde se da noticia de quién era el de la Blanca Luna, con la libertad de don Gregorio, y de otros sucesos (II, 65)

Que trata de lo que verá el que lo leyere, o lo oirá el que lo escuchare ver (II, 66)

De la resolución que tomó don Quijote de hacerse pastor y seguir la vida del campo, en tanto que se pasaba el año de su promesa, con otros sucesos en verdad gustosos y buenos (II, 67)

Que sigue al de sesenta y nueve, y trata de cosas no escusadas para la claridad desta historia (II, 70)

De los agüeros que tuvo don Quijote al entrar de su aldea, con otros sucesos que adornan y acreditan esta grande historia (II, 73)

\title{
Resumen
}

Algunos contextos que pertenecen al tejido lúdico de la transmisión de la historia en el Quijote nos hacen pensar que lo que se expresa al margen puede ser relevante, y lo que a veces es explícito puede ser irrelevante de acuerdo con el mismo juego. Así, las anotaciones marginales de los capítulos I, 9 y II, 24, cuya relevancia estudiamos, y algunos títulos que, especialmente en el Quijote de 1615, parecen estar construidos con una formulación lúdicamente irrelevante, son el resultado de incorporar los detalles del juego de la transmisión de la "historia original" a la superficie textual.

Palabras clave: Quijote; metaficción; Cide Hamete Benengeli; narración; títulos.

\begin{abstract}
Some contexts that make up the playful framework of the game of the transmission of the story in Don Quijote make us think that what is expressed on the margin of the text can be relevant, and what is sometimes explicit can be playfully irrelevant. In this way, the marginal notes we here recognize as relevant in I, 9 and II, 24, as well as some titles which, specially in the second part of Don Quixote, we considerate playfully irrelevant in its formulation, are the result of incorporating the details of the game of the transmission of the "original story" into the textual surface.
\end{abstract}

Key words: Don Quixote; metafiction; Cide Hamete Benengeli; narration; titles. 